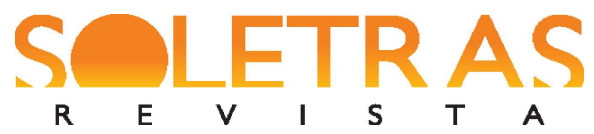

N. 38 - 2019.2 - CLÁUDIO ROBERTO VIEIRA BRAGA BRUNO CARDOSO

\title{
Imaginário da mobilidade na obra Rakushisha, de Adriana Lisboa: entre o fluxo e a fixidez
}

\author{
Cláudio Roberto Vieira Braga ${ }^{1}$ \\ Bruno Cardoso ${ }^{2}$
}

\begin{abstract}
Resumo: $\mathrm{O}$ artigo tem por objetivo analisar o romance Rakushisha, da escritora brasileira Adriana Lisboa, publicado em 2007. O recorte analítico focaliza ações e imagens de mobilidade presentes na obra, de forma que o curso da investigação evidencia como tais ações e imagens, não raro, revestem-se de profundo significado existencial, culminando com seus personagens protagonistas em situações de descoberta interior ou de "insights epifânicos sobre o eu", conforme Thompson (2011). A partir disso, com base no próprio Carl Thompson (2011), e também em Maria Zilda Ferreira Cury (2012) e Tim Cresswell (2006), o artigo evidencia como a construção discursiva de um imaginário da mobilidade projeta-se em Rakushisha por meio de uma negociação entre as instâncias metafísicas do fluxo e da fixidez. Essa negociação revela-se na instabilidade identitária das personagens protagonistas representadas, na construção de um discurso pós-nacional que vai além de essencialismos e estereótipos nacionais e, por fim, nas próprias reflexões sobre o ato de escrita, construídas na chave metafórica da viagem, no deslocamento incessante de signos.
\end{abstract}

Palavras-chave: Mobilidade versus Sedentarismo. Caminhar e Olhar. Nação e Identidade. Literatura como Viagem.

\section{Considerações iniciais}

No ano de 2007, Adriana Lisboa publica Rakushisha, como forma de homenagear o centenário da imigração japonesa no Brasil. Gesto afetivo à parte, o livro, ao abarcar aspectos que dialogam com o aparato teórico dos fenômenos de mobilidade e sua representação na literatura, despertou interesse da crítica pelo "imaginário da mobilidade" (CURY, 2012) construído pela autora. Além disso, imaginar a mobilidade em forma artística significa alinhar-se a um fenômeno antigo e, ao mesmo tempo, contemporâneo: o fenômeno da viagem em suas múltiplas tipologias.

\footnotetext{
${ }^{1}$ Doutor em Letras (Literatura Comparada) pela Universidade Federal de Minas Gerais. Atua como professor, pesquisador e orientador de literatura na Universidade de Brasília. Brasília, Brasil. E-mail: braga.claudio@gmail.com. (iD https://orcid.org/0000-0003-0687-8415.

${ }^{2}$ Doutorando em Literatura e Práticas Sociais no Programa de Pós Graduação em Literatura na Universidade de Brasília. Graduado em Língua Portuguesa e Literaturas pela Universidade Federal de Santa Catarina. Mestre em Linguística também pela UFSC. Brasília, Brasil. E-mail: brunoprofessorlp@yahoo.com.br. (i) https://orcid. org/ 0000-0001-9081-1023
} 




Isso significa dizer que a viagem como tematização não se constitui em um recurso novo na arte literária, visto que se trata de um tema que se confunde com a própria formação da literatura ocidental: a viagem está presente em obras como A odisseia, de Homero, El ingenioso hidalgo Don Quixote de La Mancha, de Miguel de Cervantes, ou na narrativa da diáspora do povo hebreu, na Bíblia Sagrada. Se o tema se apresenta antigo, a forma de explorá-lo, entretanto, revela-se atual: as múltiplas possibilidades de trabalhar o expediente temático ao longo dos últimos séculos foram abordadas em trabalhos relevantes, como, por exemplo, os de Carl Thompson (2011) e de Maria José de Queiroz (1998).

No século XXI, compete-nos enfatizar o quanto o tema da viagem vem sendo retrabalhado e ressignificado pela problematização de mundo nos projetos narrativos de uma gama de escritores de nossa época, entre os quais está Lisboa. Para pesquisadores como Maria Isabel Edom Pires (2014), pode-se aventar a possibilidade de uma vertente na literatura brasileira atual: a literatura dos deslocamentos, podendo-se incluir, nesse quadro, o projeto narrativo de Lisboa. Em nossa era, marcada por grandes fluxos e sujeitos deslocados, como salienta Edward Said (2003), a literatura, como vetor de práticas e questões do seu tempo, não passa incólume pelos condicionantes sócio-históricos de seu contexto de produção. Longe de ser um mero espelho da realidade, a ficção, pela elaboração artística, ressignifica o contexto histórico, apreendendo-o sob outro olhar, o olhar do imaginário.

Valendo-se da experiência de viagem como eixo temático em seu livro Rakushisha, Lisboa acaba por tocar em questões muito caras a este momento atual que Zygmunt Bauman (2001) denomina de "modernidade líquida". Contudo, seu romance toma distância de um estilo documental ou neorrealista: pelo contrário, Lisboa é dona de um estilo de beleza plástica, possui uma dicção sincopada e lírica que tende a se aproximar da poesia, tanto pelo lirismo quanto pelo trabalho de ritmo, bem como pela composição imagética angariada pelo uso maciço de descrições que operam, em grande parte, com dispositivos picturais, tais como os categorizados por Liliane Louvel (2006). Tais recursos plástico-narrativos aproximam a prosa da poesia e da pintura, conferindo ornamento estético ao tratamento do tema da mobilidade. Há, dessa forma, na prosa de Lisboa, uma busca por novos expedientes narrativos que possam construir um imaginário da mobilidade, de maneira que a complexidade do 
fenômeno resulte em formas narrativas também desafiadoras ${ }^{3}$ : “A mobilidade está presente, então, na variedade de enunciações que se podem registrar nas ficções contemporâneas, com a criação de novos gêneros, com a reciclagem de formas literárias tradicionais, assumindo dicções instáveis e móveis"' (CURY, 2012, p. 21).

Se deslocamentos implicam significados sociais específicos (cf. URRY, 2011, p.46), importa-nos indagar: (i). Como a experiência de mobilidade é figurada pela ficção de Lisboa? (ii). Que cosmovisão a respeito desse fenômeno, tão antigo, mas tão contemporâneo, subjaz ao tratamento estético conferido pela autora no enfrentamento desse tema? Para pensarmos estas questões, partimos das investigações teóricas de Tim Cresswell (2006), para quem o tratamento da mobilidade nos estudos humanísticos ocorre por duas vias: a metafísica da mobilidade e a metafísica do sedentarismo ou a metafísica do fluxo e a metafísica da fixidez, que serão detalhados adiante. A interpretação do romance Rakushisha, desenvolvida neste artigo, visa a demonstrar como a perspectiva de mundo revelada pelas escolhas temáticocomposicionais da escritora sugere uma espécie de negociação metafísica entre fluxo e fixidez, subjacente ao universo diegético do romance. Abordamos aspectos dessa negociação em três seções. Na primeira, ilustramos, por meio da análise de uma passagem, como a composição de uma imagem de mobilidade no romance emoldura uma dimensão existencial, aproximando o enquadramento do tema de certa dimensão e entonação metafísicas. Nas seções seguintes, discutimos como essa dimensão arquiteta-se no romance pela consecução de três eixos: identidade, nação e viagem, como signo da própria escrita ficcional.

\section{Nuances picturais do caminhar e do olhar}

Tão logo adentramos o universo ficcional de Rakushisha, sobretudo nas memórias permeadas de afetos inscritas nos diários da personagem protagonista Celina, intuímos, de imediato, a construção de uma percepção sensível sobre a experiência da viagem, que aproxima a vida do movimento, uma forma de construir uma reflexão existencial pela via da escrita viajante. Tal percepção nos conduz a verificar a presença de certa metafísica

${ }^{3}$ Para Braga e Gonçalves (2014) a percepção da complexidade dos fenômenos de mobilidade é desafiadora, sobretudo, para a crítica literária que precisa constantemente apontar caminhos para a produção literária que busca constantemente novas formas de representar esses fenômenos. Nesse sentido, a própria crítica torna-se diaspórica em seu movimento de constante revisão e atualização. 
ordenando a estrutura de Rakushisha, da mesma maneira como se poderia observar em "Espaços na e da clandestinidade", de José Leonardo Tonus (2015), para quem a presença de uma clandestinidade metafísica revela-se na dicção de todo um romance, como o autor percebe na literatura brasileira contemporânea.

De fato, os recursos estéticos mobilizados por Lisboa na confecção de sua trama conduzem para um centro comum, uma articulação entre escrita de viagem e escrita sobre a vida (THOMPSON, 2011, p.117). Esta conexão indica que os espaços exteriores explorados pelo narrador-viajante tendem a operar como uma extensão do próprio mundo interior dos personagens, de modo que a dimensão espacial se converteria em metáfora do mundo interior. Essa tendência é assinalada por Maria Zilda Ferreira Cury (2012) nos seguintes termos:

As escrituras contemporâneas muitas vezes promovem um movimento para o interior, uma intramoção, isto é, narrativas que tematizam deslocamentos no tempo e no espaço, simultaneamente a uma busca subjetiva, escritos que põem em circulação memórias individuais e coletivas, "espaços de linguagem", para onde convergem a infância, a busca das origens e do espaço identitário. (CURY, 2012, p. 21)

O movimento de intramoção ${ }^{4}$ aproxima o enredo da dimensão existencial, tal como comentado anteriormente, na medida em que Haruki e Celina, os personagens protagonistas, estão sempre na iminência de uma grande descoberta ou revelação sobre si à medida que se lançam em perambulação por terra estranha. Haruki e Celina são dois jovens desconhecidos que, desde um encontro inusitado em um vagão de trem em movimento no Rio de Janeiro resultando em uma partilha de afeto imediata - partem numa jornada ao Japão, cada um dos quais com suas próprias motivações: ele em busca de uma negociação possível entre a identidade japonesa de seus pais e sua condição de nipo-brasileiro, ela, por sua vez, em busca da superação de uma obscura experiência traumática do passado que só a viagem, a fuga do confinamento do lar doméstico, poderá propiciar. Para ambos, a viagem será salpicada de momentos de revelação interior e aprendizado.

\footnotetext{
${ }^{4}$ Reiteramos aqui, com base em Cury (2012), que o termo "intramoção", tão relevante nos estudos que ora desenvolvemos, foi cunhado pela pesquisadora Nubia Hanciau no Colóquio Mobilidades Culturais: agentes e processos, na UFMG, em agosto de 2007.
} 
Tal conotação metafísica do enredo revela-se em algumas passagens permeadas pelo sentimento de epifania, no sentido joyceano, declinado de um cultivo da sensibilidade do olhar viajante, que perscruta o mundo com um novo sentimento, um novo ethos:

A chuva fina deixava o mundo luminoso diante dos olhos de Haruki. O asfalto puído da Machado de Assis brilhava. Os carros estacionados brilhavam. Folhas de árvores. Grades à entrada dos edifícios. Até o som das coisas brilhava na chuva, as rodas dos carros sobre o asfalto, uma freada brusca e a buzina, o rádio do porteiro. Era preciso reconhecer e reverenciar esses momentos. Eles eram rápidos e raros. Momentos em que sem nenhum motivo aparente tudo parecia entrar nos eixos, ajustar-se, encaixar-se. Acabavam-se as perguntas e a necessidade delas. Acabava-se a pressa, o ter aonde ir, o vir de algum lugar. Simplesmente as solas dos sapatos batiam na calçada úmida e pronto, o mundo prescindia de outros significados. Um pé depois do outro. Momentos rápidos e raros. Aquele ali se desfez de repente, no cruzamento com a rua do Catete. Haruki notou que perdia alguma coisa, chegou a olhar para trás automaticamente, para ver se dava com um pedaço de si caído na calçada. Mas era o instante que se desmanchava, colher de sal dentro d'água. E Haruki sacudia a colherinha, desmanchava o instante, porque não tinha como ser diferente, se a gente não mata as epifanias elas nos matam (LISBOA, 2014, p. 24).

Caminhar e olhar estão imbricados no excerto acima, em que o viajante Haruki vivencia um momento epifânico. O caminhar como ato que proporciona reflexão filosófica já foi descrito com profundidade por pensadores como Kant, Rousseau e Thoreau. Henry David Thoreau, por exemplo, considera o caminhar um ato que proporciona ao caminhante uma "liberdade comparativa": "A caminhada de que falo nada tem a ver com praticar exercício [...]. Ela é, na verdade, a empreitada e a aventura do dia" (THOREAU, 2006, p. 73). Instintiva, a caminhada de que fala o autor em seus escritos está relacionada com o ambiente natural, resultando em maior harmonia e equilíbrio: "haverá muito mais ar e sol em nossos pensamentos" (THOREAU 2006, p. 74). Haruki, apesar de caminhar em área urbana, o faz sob o feito de um elemento natural, a chuva fina; ela deixa o mundo luminoso diante de seus olhos, se revelando um componente essencial para a concretização de seu raro momento de descoberta epifânica.

Inerente ao caminhar, o olhar vem impregnado de uma sensibilidade, de modo a implicar uma nova forma de captar/perscrutar o mundo. Cardoso (1988), ao demarcar 
diferenças entre o olhar e o ver, estabelece uma espécie de fenomenologia do olhar do etnólogo, que também se estende ao olhar do viajante, apresentando algumas considerações que se tornam pertinentes para interpretar os gestos de contemplação em Rakushisha:

O olhar não descansa sobre a paisagem contínua de um espaço inteiramente articulado, mas se enreda nos interstícios de extensões descontínuas, desconcertadas pelo estranhamento [...] por isso o olhar não acumula e não abarca, mas procura, não deriva sobre uma superfície plana, mas escava, fixa e fura, mirando as frestas deste mundo instável e deslizante, que instiga e provoca a cada instante sua empresa de inspecção e interrogação (CARDOSO, 1988, p.349)

O que dista o olhar da visão é, portanto, um ethos, uma postura por parte do caminhante observador, que exerce sobre o mundo contemplado uma postura mais ativa do que passiva, permitindo-se ser surpreendido e interpelado pela realidade exterior, sobretudo nas experiências de estranhamento que tais perscrutações podem engendrar. Se Cardoso não lança mão do termo "epifania", ele comparece, entretanto, nas reflexões de Thompson (2011) quanto às novas configurações narrativas do gênero relato de viagem, que primam pela narrativa em primeira pessoa, bem como sua filiação à estética subjetiva do período romântico e o tipo de relato de viagem, que começara a ser produzido naquele momento:

With Romanticism, moreover, there came an increasing valorization of travel as a key means by which such epiphanic insights into the self might be achieved, and which them the greater degree of authenticity, autonomy and self-realization that is usually assumed to follow on from such selfknowledge. Much of William Wordsworth's poetry, for example, invests travel with this existential significant, repeatedly depicting, the poet's rambles and walking tours as journeys that culminate in moments of personal revelation and renovation.(THOMPSON, 2011, p. 115)

\footnotetext{
5 Tradução: "Com o romantismo, além disso, surgiu uma crescente valorização das viagens como um meiochave pelo qual tais insights epifânicos sobre o eu poderiam ser alcançadas, e delas um maior grau de autenticidade, autonomia e autorrealização que geralmente é assumido como decorrente de tal autoconhecimento. Grande parte da poesia de William Wordsworth, por exemplo, investe nas viagens com esse significado existencial, repetidamente retratando os passeios e incursões a pé do poeta como jornadas que culminam em momentos de revelação e renovação pessoal" (THOMPSON, 2011, p. 115).
} 


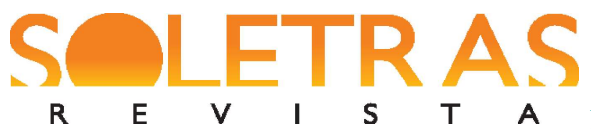

Esse instante epifânico que enreda o olhar do viajante e o insuflam com uma nova revelação acerca de si, tal como postulado por Thompson, revela-se claramente no excerto acima, retirado de Rakushisha. Nesse - o narrador heterodiegético, outra voz além de Haruki, Celina e o poeta Matsuo Bashō a dar curso ao enredo- constrói um discurso reflexivo sobre as epifanias que se entreveem em instantes corriqueiros, constituídos por ações banais e habituais, tal como a ida diária a uma estação de metrô.

Há que se destacar também que o insight epifânico na passagem ora analisada impacta o leitor devido ao uso requintado daquilo que Louvel (2006) denominou descrição pictural. Estudiosa das relações entre literatura e pintura, Louvel afirma que a descrição pictural consiste, através das técnicas de descrição empregadas por um determinado autor, em aproximar a cena descrita de um quadro pintado. Para alcançar esse efeito estético, o escritor lança mão de certos dispositivos como: marcadores de enquadramento, metáforas, comparações, hipotipose, léxicos especializados que abarquem as luzes, as cores, sons, formas, massas, simetrias, dissimetrias, bem como elipses, cortes, metáforas, o enquadramento pelo uso do pretérito imperfeito e tantos outros recursos elencados pela pesquisadora (LOUVEL, 2006, p. 210).

A hipotipose é um ornamento de linguagem da retórica clássica, cuja definição diz respeito ao efeito de vivacidade com o qual uma cena é descrita ao leitor, de modo que o faça sentir-se colocado diante da cena narrada. No trecho de Rakushisha acima mencionado, que elegemos para a análise, a hipotipose é obviamente caracterizada na medida em que todos os recursos plásticos convergem para a consecução de um verdadeiro quadro-vivo, pintura narrada, que reitera e potencializa os instantes de epifania vividos pelo personagem. Tais instantes, por sua vez, são acentuados, no excerto, por uma série de orações curtas, assindéticas, num efeito de corte cinematográfico, como se fossem flashes captando, de forma pontual, esses átimos epifânicos. Do léxico, cujo campo semântico especializado evoca textura, luzes, sons, convergência de sensações variadas, até a presença explícita de um marcador de enquadramento, "o mundo luminoso diante dos olhos de Haruki", obtém-se o belo efeito estético de formar-se no imaginário do leitor um quadro-vivo, que repisa esse instante de grande relevo existencial. 
A presença da hipotipose, como recurso plástico e retórico no romance, está, sobretudo, nesses momentos de grande contemplação sobre o mundo exterior, de modo que seu uso sublinha o impacto que os movimentos dos pés no caminhar e dos olhos no olhar produzem no sujeito observador em termos de revelação e de descoberta de si. Ocorrerá com a personagem Celina já quando clandestina no Japão, bem como voltará a ocorrer com Haruki em sua jornada na terra natal de seus ancestrais. Em outras palavras, o uso dos recursos picturais potencializa, por sua vez, em momentos estratégicos, o calibre metafísico desejado pela autora na dicção de sua prosa. Compete perguntar, então, sobre como essa metafísica se delineia na ficção de Lisboa. Pode-se assumir que sua narrativa insiste numa espécie de negociação entre o estático e o movente ou, nos termos de Cresswell (2006) entre uma metafísica da fixidez e uma metafísica do fluxo?

\section{Nação e identidade: tensões entre mobilidade e sedentarismo}

Após termos detectado, em Rakushisha, a presença de uma dicção metafísica como fio a percorrer o desenvolvimento do enredo, faz-se necessário detalhar as noções de metafísica da fixidez e do fluxo de Cresswell (2006), que são de importância capital para o objetivo aqui proposto, isto é, o de compreender, de modo mais detalhado, a cosmovisão esboçada no romance de Lisboa. No livro On the move: mobility in the modern Western world, Cresswell detalha esses dois modos de compreensão do mundo pensados à luz do campo semântico da mobilidade: a metafísica da fixidez e a metafísica do fluxo:

The first sees mobility through the lens of place, rootedness, spatial order, and belonging. Mobility, in this formulation, is seen as morally and ideologically suspect, a by-product of a world arranged through place and spatial order. The second puts mobility first, has little time for notions of attachment to place, and revels in notions of flow, flux, and dynamism. Place is portrayed as stuck in the past, overly confining, and possibly reactionary. In both cases, the moral geographies of place and mobility interact to inform ontology, epistemology, and politics as well as practice and material culture (CRESSWELL, 2005, p. 26)

\footnotetext{
${ }^{6}$ Tradução: “A primeira vê a mobilidade através das lentes do lugar, do enraizamento, da ordem espacial e do pertencimento. A mobilidade, nessa formulação, é vista como moral e ideologicamente suspeita, um subproduto 
A reboque dessas duas metafísicas, advém uma série de sentimentos e percepções, instalados, sobretudo, no campo discursivo envolvendo os conceitos de identidade e de nação, mas também na esfera de valores que são atribuídos a uma série de sujeitos - elencados em uma espécie, grosso modo, de categorias da mobilidade - cuja vida se inscreve na experiência de deslocamento. No caso da percepção sedentária de mundo,

The drifter, the shiftless, the refugee, and the asylum seeker have been inscribed with immoral intent. So, too, the traveling salesman, the gypsytraveler, and the so-called wandering Jew. These have all been portrayed as figures of mobile threat in need of straightening out and discipline (CRESSWELL, 2005, p. 26) ${ }^{7}$

No anelo de se dividir o mundo em limites territoriais cada vez mais precisos e delimitados, vislumbra-se um modo de pensar de forma fixada, limitada e enraizada, que reafirma e potencializa a segmentação do mundo em rótulos como nações, estados, países e lugares, eivados de valores do senso comum vinculados a uma percepção sedentária de existência. Dessa forma, o estrangeiro, o migrante, o clandestino afiguram-se como uma ameaça indesejada e inoportuna à soberania nacional. A deflagração de ondas de hostilidade a migrantes e refugiados no século XXI, como, por exemplo, aos venezuelanos, ocorrida em agosto de 2018 em Pacaraima, no Norte do Brasil, pode ser citada como um exemplo atual para esse argumento desenvolvido por Cresswell.

No caso da metafísica nômade, o estudioso apresenta-a como alinhada a uma valoração positiva, feita de sentimentos de progresso, liberdade e mudança, de modo que, num mundo que se sente e se percebe cada vez mais movente, torna-se inevitável, aos estudos humanísticos, pensar sobre tal mundo através de um pensamento que também seja nômade. James Clifford, Marc Augé, Deleuze e Guattari e Michel de Certeau são alguns dos teóricos

de um mundo organizado por ordenamento local e espacial. O segundo coloca a mobilidade em primeiro lugar, tem pouco tempo para as noções de apego ao lugar e apraz-se em noções de fluidez, fluxo e dinamismo. O lugar é retratado como preso ao passado, excessivamente confinado e possivelmente reacionário. Em ambos os casos, as geografias morais do lugar e da mobilidade interagem para fundamentar uma ontologia, epistemologia e política, bem como uma determinada prática e cultura material".

${ }^{7}$ Tradução: "O andarilho, o sem-rumo, o refugiado e o requerente de asilo foram inscritos com intenção imoral. Assim também o vendedor ambulante, o viajante cigano e o chamado judeu errante. Todos eles foram retratados como figuras de ameaças móveis que precisam ser endireitadas e disciplinadas'”(CRESSWELL, 2005, p. 26). 
elencados por Cresswell como expoentes de uma metafísica do nomadismo, a partir da qual se problematizam discursos essencialistas e fundacionais, bem como discursos de representação. Um tema central que emerge com a metafísica nômade é a equação que liga a mobilidade a formas de poder subalterno, no que a mobilidade adquire um papel nuclear nas práticas de transgressão e de resistência, principalmente contra formas estabilizadas de ordenamento e de disciplina.

Apesar de apresentar duas metafísicas que orbitam em polos extremos, o teórico finaliza ponderando que, em nossa vida diária, vivemos transitando por um continuum entre as duas metafísicas, e, dificilmente, incorporamo-las isoladamente, de tal sorte que ora buscamos um equilíbrio entre fixidez e fluxo, ora nos colocamos em conflito interior entre esses dois polos, tensionando-os, articulando-os, almejando uma negociação possível entre ambos. Para fins de análise, vamos nos deter no delineamento da forma como a metafísica da mobilidade se apresenta no romance de Lisboa. Nesse sentido, a abertura para a vivência de uma experiência de mobilidade vai permitir, como demonstraremos, aos protagonistas Celina e Harukium reposicionamento identitário que resultará na possibilidade de superação de traumas e dores do passado. Disso decorre o papel de relevo que o discurso ficcional confere à figura anatômica dos pés: “Um dia Celina se deu conta de que o que mais lhe importava em seu corpo eram os pés. Onde seus pés estivessem no momento estaria sua alma"' (LISBOA, 2007 p. 29).

Contudo, a prevalência de uma metafísica nômade não se apresenta no livro sem pontos de tensão. Tal tensão, entre mobilidade e sedentarismo, inscreve-se, por exemplo, de forma muito delicada, na escolha do nome do personagem Haruki, em virtude de seu significado:

Seu sobrenome, Ishikawa, compunha-se de dois ideogramas triviais [...] Ele sabia. O primeiro, de cinco traços, significava pedra. O segundo, de apenas três, significava rio. Herança deixada por Ishikawa pai: a ideia de um rio correndo sobre pedras silenciosas, passando, apenas, em meio a um mundo de sonhos. Haruki sabia que um rio falava de dúvidas. Nunca se atinha a si mesmo. Nunca se cristalizava na pedra que o acolhia. Ao mesmo tempo, a pedra, que parecia eterna, ia se gastando e se deslocando da maneira mais contundente de todas - sem alarde, sem aviso. O rio e a pedra, no sobrenome que Haruki havia herdado do pai, eram coisas que contradiziam gravemente a si mesmas (LISBOA, 2007, p. 49) 
Por meio da contraposição de motivos, o rio e a pedra, duas imagens que metaforizam o embate entre fluxo e fixo, a escritora representa as duas metafísicas que prevalecem na cosmovisão ocidental, conforme Cresswell (2006). Se o rio implica movimento incessante, dúvidas, efemeridade, a pedra, por outro lado, implica fixidez, eternidade, apego ao que passou, a solidez de certezas tidas como insofismáveis. Todavia, ainda assim, a composição plástica da cena, como num quadro de natureza-morta, apreende essa pedra em decomposição sutil e em deslocamento inevitável, indicando que o fixo pode ser apenas aparentemente estático, e priorizando o rio com seu fluxo soberano. O rio figura-se como se estivesse em diálogo filosófico com o rio de Heráclito: é aquele onde ninguém consegue banhar-se duas vezes, pois, quando se o faz, as águas já são outras. Assim, o rio é motivo singular, irrepetível, poderoso em seu fluxo indomável, e seu uso feito por Lisboa coaduna-se com uma percepção de mundo mais próxima da metafísica nômade, ainda que não abra mão do jogo de equilíbrio entre ela e a metafísica sedentária.

Ishikawa, sobrenome de Haruki que nos permite pensar a tensão e a ambiguidade entre o fixo e o fluido, ${ }^{8}$ permite-nos expandir a noção da metafísica do sedentarismo traduzida, entre outros aspectos, na noção de apego a um lugar. Tal apego é marca predominante nos discursos essencialistas sobre identidade e nação, que implicam, segundo Stuart Hall (1999), um determinado referente estável sobre o qual os sujeitos geralmente ancoram suas noções de pertencimento e a partir do qual possam imaginar-se como pertencentes a uma nação (ANDERSON, 2008). Lisboa afasta-se de uma visão essencialista, tanto de identidade quanto de nação, por meio do sobrenome de Haruki. Ishikawa, ao carregar a tensão e a ambiguidade entre o fixo e o fluido, indica a identificação intersticial nipo-brasileira de Haruki, fazendo contraponto a discursos de afirmação identitária ou busca definitiva de identidade. Ishikawa indica que a autora opta por trabalhar identidade como um conceito em construção, em devir, em viagem, para o qual a forma escrita-de-viagem se revela imprescindível para a representação de um eu-itinerante (THOMPSON, 2011). Além do nome, Haruki carrega os traços físicos da etnia japonesa, que se contrapõem à sua falta de apego às tradições ancestrais

\footnotetext{
${ }^{8} \mathrm{Na}$ elaboração ficcional, nem sempre nomes próprios são empregados de modo gratuito. Vertido em símbolo literário, o nome próprio pode impregnar-se de nuances semânticas outras, dado o universo diegético em que é empregado. Para Gerus-Tarnawecky (1968), à luz da onomástica literária, cumpre ao analista observar a função expressiva e estilística que o emprego de certos nomes próprios pode suscitar em determinada obra literária. No Brasil, sobre onomástica literária, convém destacar também o trabalho de Ana Maria Machado (1976), no qual a pesquisadora analisa a função expressiva de que os nomes próprios se revestem nas narrativas do escritor João Guimarães Rosa.
} 
(LISBOA, 2007, p.53), aos códigos, costumes e religião (LISBOA, 2007, p.54), bem como à língua do país de seus antepassados (LISBOA, 2007, p. 26). Seu desapego é motivo pelo qual alimenta um remorso por nunca ter satisfeito seu pai com o cultivo das tradições asiáticas (LISBOA, 2007, p. 100). Assim, Haruki, nascido e criado no Brasil, país onde seus pais protagonizaram um movimento diaspórico no início do século passado, distancia-se de marcas fixas de referência identitária. Haruki é definido pelo desenraizamento e pelas rotas alternativas:

\begin{abstract}
Deve haver um modo, quem sabe, de partir em viagem e não regressar mais. Reduzir-se à mochila que vai às costas e a umas poucas mudas de roupa. Reduzir-se, ou agigantar-se, a uma ausência de casa própria e cidadania, esfacelar o papel pega-mosca do cotidiano e fazer dele mesmo, cotidiano, uma aventura infinitamente deslocável. Descolável. Desgrudá-lo do chão. Levantar os pés para caminhar, estudar a bússola e o mapa, mas randomizar todos os gestos. Traçar uma reta, menor caminho entre dois pontos, e picotála com a tesoura, apagar trechos com a borracha, dissimular outros com o esfuminho, despistá-la em curvas. De tal modo a esquecer que um dia chegou a ser uma reta, dotada de ponto final. De objetivo. Desobjetivar-se. Esse, o território realmente virgem - o único. Assumir como um sentido a falta de sentido da vida. Em todos os sentidos. (LISBOA, 2007, p. 80)
\end{abstract}

As divagações interiores de Haruki, nesse excerto, explicitam o desejo de uma total desvinculação em relação a espaços como casa própria e cidadania - esta última uma referência direta à nação - além da ausência da necessidade de retorno, a redução dos pertences ao mínimo, representando a eliminação completa de amarras, para se viver a “aventura infinitamente deslocável”. Para Haruki - e o mesmo poderá ser dito sobre Celina - a noção de viver verte-se na possibilidade desse movimento, uma espécie de enraizamento nômade que articula trajetórias descomplicadas, retas impossíveis no complicado sistema de fronteiras nacionais que insiste em impor identidades. Até mesmo as retas imaginadas por Haruki poderiam deixar de serem retas, sendo despistadas em curvas e, principalmente, serem infinitas, isto é, sem ponto final. Assim sendo, Lisboa, sem prescindir da tensão e da ambiguidade entre as metafísicas do fluxo e da fixidez, confere, por meio do anseio de Haruki, uma paradoxal "estabilidade no movimento", que elimina referências fixas a partir das quais os sujeitos tendem a se ancorar para definirem-se de forma exata, e que passa ao 
largo das noções de pátria e nação como formas de pertencimento. Dessa maneira, as referências construídas no espaço percorrido, em viagem, se revelam mais viáveis por respeitarem a provisoriedade das identificações, por estarem prontas a serem transmutadas em novas e provisórias referências, por possibilitarem novas rotas de viagem "despistadas em curvas" e "dissimuladas com esfuminho". Adicionalmente, essas referências, vale dizer, ao firmarem a noção de movimento como estabilidade a sujeitos como Haruki, remetem-nos à noção de lar, correntemente conectada à estabilidade, como se vê, de fato, simbolizado na filosofia de viagem do poeta Bashō:

A viagem sempre é pela viagem em si. É para ter a estrada outra vez debaixo dos pés. O lar de Bashō, como dos navegantes, como o daqueles homens que passam a vida a conduzir cavalos, é em qualquer parte. É o lugar aonde a viagem decidir levá-lo. (LISBOA, 2007, p. 121)

Se a possibilidade de se fazer um lar "em qualquer parte" é condição primordial para que Haruki possa elaborar a si mesmo, o mesmo poderá ser dito a respeito de Celina. Para ela, o deslocamento e a acolhida em terra exógena, o colocar-se à distância da redoma do espaço privado de seu lar no Brasil, onde memórias traumáticas anulam sua existência, permitem-lhe visualizar para si um lar em movimento e novas possibilidades de identificação e de reposicionamento como sujeito: "Como seria possível que se sentisse em casa ali, se não entendia nem mesmo as inscrições nas placas ao seu redor? Se não tirava sentido das palavras ditas ao seu redor? Mas era uma. Era uma casa segura'” (LISBOA, 2007, p.57). Ou ainda: “Gosto dessa familiaridade da estranheza, de que, de repente, me dou conta. Gosto de me sentir assim alheada, alguém que não pertence, não entende, não fala' (LISBOA, 2007, p.133). A resposta às indagações de Celina sobre como ela se sente à vontade na casinha que ocupa no Japão começa pelo entendimento de que a viagem resulta em uma distância, uma desconexão dos elementos de perda e de dor que passam a impregnar seu lar no Brasil, o que confere a ela alívio. O novo espaço também é caracterizado por uma nova percepção de lar,uma espécie de tenda itinerante, dissociada das amarras limitadoras do passado. Acrescenta-se a isso a "familiaridade da estranheza" no novo ambiente, no qual Celina se 
sente bem, sem os vínculos de pertencimento, de língua e de entendimento, vínculos associados à nação e às identidades nacionais, que são desfeitos no enredo de Rakushisha.

Portanto, no romance, a identidade é configurada por elementos de fluidez, ao mesmo tempo em que, ao conceito de nação, é atribuído um caráter difuso, sem contornos bem delimitados. Sobre a nação japonesa em Rakushisha, nota-se sua representação elaborada com fissuras em suas margens. Como as culturas viajam (GILROY, 2001), colocando-se em confluência, o Japão contemporâneo surge no romance caracterizado, por exemplo, por uma cadeia ocidental de Donuts (LISBOA, 2007, p. 76), uma rede de Starbucks estadunidense, que comercializa frapuccinos de chá verde, bem como um clube de ofurôs comunitário com vista para um pagode (LISBOA, 2007, p.145).

Assim sendo, quando ficcionaliza a nação, o que o faz apenas como objetivo secundário, Lisboa revela uma tendência a fugir a estereótipos, a imagens fixas alimentadas por discursos nacionalistas, que acabam eliminando a heterogeneidade e as contradições internas a toda nação. Com efeito, revela-se, no projeto ficcional de Lisboa, a vontade de " "pegar com os olhos um chão que era vários, costurados dentro de uma mesma fronteira", (LISBOA, 2007, p.52). Nisso, reside, ao longo da escrita de Rakushisha, uma perspectiva pósnacional", no sentido propalado por Bhabha (2005, p. 242), de "rasurar fronteiras totalizadoras", uma perspectiva que se pode alinhar, portanto, com a noção de metafísica da mobilidade de Cresswell (2006). Na narrativa, as fissuras abertas nas fronteiras da nação dão visibilidade à heterogeneidade e às contradições no interior do território nacional, escapando a imagens estereotipadas que apagam diferenças internas: "colocar uma cerejeira frutada no lugar do jatobá. Um samuraizinho no lugar do menino descalço”’ (LISBOA, 2007, p. 52), são

\footnotetext{
${ }^{9}$ Em algumas de suas entrevistas, a autora relaciona o seu lugar de fala, como escritora que escreve em língua portuguesa, mas que vive fora do país, com o seu projeto de escrita destituído da ambição de falar sobre o Brasil. Ao ser questionada sobre como é escrever em uma língua completamente diferente daquela onde reside atualmente, no caso os Estados Unidos, Lisboa problematiza o vínculo estrito entre escritor e nação: 'É uma coisa estranhamente esquizofrênica pra mim, porque eu sou daqui, mas não sou daqui, escrevo em português, mas venho aqui uma vez, duas vezes por ano [...] o que gera essa sensação de eu não saber muito bem onde eu tô, né, porque tô lá nos Estados Unidos, mas não escrevo em inglês [...] Além do que existe também, isso não só nos Estados Unidos, mas em outros países também, mas eu acho que principalmente lá, existe muito essa expectativa de que você, sé é um autor brasileiro, então o leitor americano vai ler o seu livro em busca de algum Brasil, já que você é brasileiro, então obviamente você vai falar do Brasil, embora eles, os gringos, não precisem falar do país deles, mas nós, como periferia, precisamos falar, então, de algum modo, eles querem aprender alguma coisa sobre o Brasil através dos livros de um autor brasileiro, ou senegalês, ou seja lá de onde for, eles querem ter esse contato com a cultura também, então você acaba meio que em um gueto dentro de um gueto, porque eu não tenho, eu, pessoalmente, não tenho esse compromisso de falar do Brasil, eu posso até falar, mas não é um projeto meu, eu não tenho como projeto falar do Brasil’”.

Ver https://www.youtube.com/watch? $\mathrm{v}=\mathrm{j} 4 \mathrm{KBOdUKSy} 8$.
} 
pequenas ações produtoras de novas imagens, novas enunciações que abarcam a complexidade movente de uma conjuntura pós-nacional.

Assim, em Rakushisha, a representação de nação em fissuras e de identidade em construção, em devir ou em viagem, é construída no espaço de negociação entre as metafísicas do fluxo e da fixidez.

\section{Metáforas, repetições referências intertextuais e diários: literatura é viagem}

No caminho interpretativo trilhado até aqui, temos perscrutado os eixos de configuração de uma metafísica da mobilidade subjacente ao plano diegético do romance Rakushisha, de modo a atestar como esse discurso metafísico se delineia, artisticamente, num jogo de negociação entre o fluxo e a fixidez ao longo do romance. Vamos, nesta seção, deternos sobre como Adriana Lisboa, ao oferecer sua própria concepção de narrativa de viagem, problematiza o próprio fazer literário, e consequentemente a noção de representação, a partir desse espaço de negociação metafísica. Como consequência, percebe-se um alinhamento por parte da escrita da autora com uma tendência que se revela produtiva nas narrativas moventes do século XXI: a escrita de viagem como possibilidade de repensar os próprios limites da representação. Apresentamos anteriormente alguns dos argumentos elencados por Thompson (2011), principalmente aqueles que articulam o relato de viagem com a problematização acerca do estatuto ontológico do eu. Contudo, mais ao final do capítulo "'Revealing the self', Thompson deixa entrever a relação próxima que a escrita de viagem guarda com a tendência estética pós-moderna, de ruptura com formatos tradicionais de narrativa:

Postmodernism is [...] born of a desire to subvert both the conventions and the authority traditionally associated with many Western genres, disciplines e discourses. With regard to travel writing, this can involve playing against traditional narrative and stylistic expectations in a variety of ways (THOMPSON, 2011, p. 127). ${ }^{10}$

${ }^{10}$ Tradução: "O pós-modernismo é [...] nascido de um desejo de subverter tanto as convenções quanto a autoridade tradicionalmente associadas a muitos gêneros, disciplinas e discursos ocidentais. No que diz respeito à escrita de viagens, isso pode envolver jogar contra a narrativa tradicional e as expectativas estilísticas em sua variedade de formas" (THOMPSON, 2011, p. 127). 


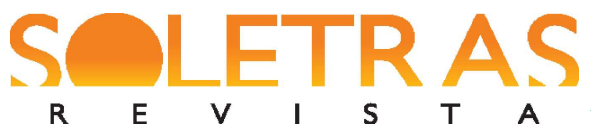

Imbuídos dessa premissa, podemos aventar, como implicação do pensamento de Thompson, que, na escrita de viagem de Lisboa, a viagem opera como um signo que metaforiza a própria escrita ficcional, cuja condição reside no caráter imprevisível, polissêmico do signo, de sorte que tal condição potencializa os sentidos, estendendo-os ao infinito. Se a condição sine qua non para a escrita literária é a potência múltipla do sentido, a metáfora aporta, por conseguinte, como um recurso nuclear para a constituição daquilo que os formalistas russos denominavam literariedade. Raúl Antelo (2012), em “Mas, onde fica a viagem?", discorre sobre a etimologia da palavra "metáfora" e nos relembra a associação que essa palavra apresenta com a ação de deslocar-se: de origem grega, meta significa“'além”, e phorein é "transportar de um lugar para outro". Em suma, a metáfora, ao designar a relação de semelhança entre palavras comparativamente, fá-lo como num gesto de deslocamento que dá novas colorações semânticas ao signo. "O relato de viagem é infinito assim como a metáfora é infinita", afirma Antelo (2012, p. 17).

A partir disso, podemos inferir que a aproximação entre viagem e metáfora torna-se intrínseca à aproximação entre viagem e escrita de maneira geral que podemos detectar em Rakushisha. No romance, a referência intertextual aos diários de viagem do poeta Bashō, simboliza a relação viagem/metáfora/escrita, que se coloca em analogia com os registros grafados pela própria personagem Celina: no ato de escrever seu próprio diário, ela deixa claro que viajar implica elaborar-se a si mesmo, descobrir-se a si mesmo: "Viajar é pela viagem em si. É para ter o caminho debaixo dos pés"' (LISBOA, 2007, p.180). Aqui poderíamos, no exercício de apreendera viagem pela viagem, segundo a narradora que mantém o diário, sugerir que viajar é "pela escrita de si", tendo em vista que o ensinamento e a experiência emanados da prática da viagem são convertidos em autoconhecimento e em escrita, gesto que concretiza o aprendizado advindo do movimento. Um pouco mais adiante, a relação pari passu entre viagem e escrita então se desvela em algo mais abrangente:

Essa é a verdade da viagem. Eu não sabia. A viagem nos ensina algumas coisas. Que a vida é o caminho e não o ponto fixo no espaço. Que nós somos feito a passagem dos dias e dos meses e dos anos, como escreveu o poeta japonês Matsuo Bashō num diário de viagem, e aquilo que possuímos de fato, nosso único bem, é a capacidade de locomoção. É o talento para viajar (LISBOA, 2007, p.187). 


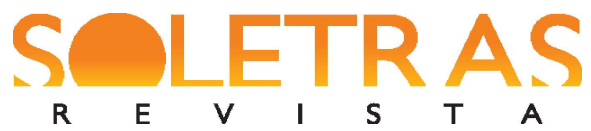

Deste modo, viagem e escrita estão ligadas à vida: viajar é viver, a vida é o caminho, o registro em forma de diário é o exercício de elaboração e de compreensão. Por fim, nossa capacidade de locomoção, isto é, nosso talento para viajar, são verdadeiramente saber continuar vivendo, apesar das adversidades da própria vida. Lisboa, que não economiza no manejo com as metáforas, ao construir essa perspectiva de vida constrói também o conceito de sua literatura, ligada aos processos de si e da vida, na interseção metafísica entre fluxo e fixidez. Para tal construção, se utiliza de recursos narrativos como o uso da repetição para evocar o caráter volátil do enunciado, conceito bastante caro a Mikhail Bakhtin (2011). Para ele, o enunciado, ao contrário da frase, implica ganho de sentido conforme a situação de enunciação. $\mathrm{O}$ enunciado é sempre irrepetível, mesmo que apresente em sua tessitura a mesma materialidade de outro enunciado já utilizado. Isso implica uma leitura mais instável do signo, o que aproximaria a noção de linguagem em Bakhtin de uma metafísica da mobilidade. Essa percepção, sobre as implicações metafísicas do pensamento bakhtiniano, tem reverberação nas reflexões teóricas de Cresswell (2006), no que se refere à visão de mundo carnavalesca de Bakhtin.

A partir dessa aproximação, aventamos que a repetição se apresenta como um recurso narrativo no romance de Lisboa com o qual se insinua uma relação entre linguagem e movimento, ou entre signo e viagem. A citação acima, extraída do romance, uma das mais emblemáticas de Rakushisha, na qual Celina apresenta o talento para viajar como o bem maior descoberto por ela, aparece também no início do livro, logo na primeira menção ao diário de Celina. Este, porém, fora escrito no dia 17 de junho de um ano impreciso, aquele, por outro lado, no dia 28 de junho de um ano também sem marcas precisas, já decorridos alguns dias da presença de Celina em terra estrangeira. Nesse intervalo, há um ganho de experiência, um acúmulo de imagens, de epifanias, de descobertas sobre si. Trata-se, portanto, da mesma frase, mas não do mesmo enunciado, visto que aparece no romance sob contextos volitivo-emocionais totalmente diferentes, encapsulado por situações de enunciação totalmente díspares. Em Rakushisha, portanto, frase e enunciado podem ser lidos como outra faceta da negociação entre o fluxo e a fixidez, visto que, nessa acepção, a repetição implica deslocamento. Além disso, a Celina que se apossa desse enunciado já não é a mesma ao terminar a escrita do seu diário de viagem. 
Essa percepção da linguagem como movimento incessante de signos em tensão com a fixidez perpassa toda a confecção do romance. Não somente as repetições encapsulam-se sob novos matizes, mas o próprio jogo de citações textuais confere ao texto citado um novo torneado estético. Assim, os diários de Bashō são referenciados no romance de Lisboa por intermédio de uma estrutura de palimpsesto, conceito proposto por Gérard Genette (1995) para evocar o jogo de escrita de um texto sobre o outro, outorgando novas camadas ao texto primevo. Essa estrutura em palimpsesto é mencionada no romance, em forma de pista metanarrativa, quando Celina descreve o apartamento em que se encontra hospedada no Japão:

As pessoas que moraram antes neste apartamento deixaram coisas, e o pequeno espaço é uma pequena confluência do mundo também, um palimpsesto de gente que passou, mas quis firmar o atestado de sua passagem numa ou noutra pequena gentileza (LISBOA, 2007, p. 50).

Ou ainda nesta passagem em que Haruki relembra um poema de Bashō sobre a neve. Trata-se de uma passagem repleta de sobreposições de imagens e de sinestesias e que, mesmo com economia de meios, revela um verdadeiro palimpsesto metaforizado em forma de imagem plástica, decorrente do uso apropriado da técnica de descrição pictural, mais precisamente da hipotipose (LOUVEL, 2006):

Neve e neve. Neve mais neve. Neve na neve. Branco sobre branco. Branco se acrescentando ao branco. Uma gentileza plástica, uma concessão. Não havia modo de aferir a imagem da neve sobre a neve se não com aquelas palavras. Yukitoyuki. Neve e neve. Dizer menos seria pouco. Dizer outra coisa seria acessório. Como acessório era tudo o que Haruki pudesse pensar sobre aquele problema. Bastava deixá-lo ficar, deixá-lo cair como neve sobre neve no fundo imaginativo de seus olhos. Ouvir seu silêncio algodoado e branco. (LISBOA, 2007, p. 148).

A evocação de uma imagem construída por camadas sobrepostas em uma passagem de alta carga metalingüística converte-a também em pista deixada pela autora quanto à estrutura 
composicional de seu romance, esculpido verbalmente em formato de palimpsesto, onde sobreposição implica alguma "concessão", onde o texto original se despe de suas nuances originais para, como gentileza plástica, alargar-se a novos horizontes de significado. Com isso, a escritura do diário de Celina pari passu com as referências ao diário de Bashō produz um efeito plástico e retórico de amplificação, construído através do contraponto de vozes - a voz do poeta e a voz de Celina - por meio das quais uma dicção ecoa a outra, ressignifica a outra, ou desloca a outra.

No Japão, Haruki descobre traços de si ao mesmo tempo em que procura os vestígios estéticos dos trajetos palmilhados pelo poeta Bashō. Em Kyoto, Celina deambula em terra estranha carregando na mochila o seu diário e o diário do poeta Bashō. Nesse movimento, há sobreposição, ressignificação, há o signo instável e volátil potencializando os efeitos estéticos da boa literatura.

Em Rakushisha, com efeito, as pistas metanarrativas e a concepção de literatura nelas implicadas se constituem como um dos eixos que enformam o espaço intersecional que congrega as metafísicas do fluxo e da fixidez.

\section{Considerações finais}

Rakushisha se apresenta como um romance que prima por uma composição rica em camadas e por uma prosa de qualidade estética, por uma dicção imbuída de lirismo e pelo uso de nuances picturais, propiciando o efeito de imagens que se apresentam como verdadeiros quadros-vivos ao leitor, numa aproximação inevitável entre prosa e pintura, através do recurso retórico da hipotipose, tal como analisamos, com base em Liliane Louvel (2006). Esse entrelaçamento entre tema e estrutura composicional permite que a interpretação de mundo da autora, quanto às experiências de mobilidade e seus efeitos vivenciados pelo sujeito pósmoderno, seja plasmada artisticamente com êxito no curso do romance.

A análise empreendida lançou foco sobre essa visão de mundo revelada, no plano diegético, sob a forma de uma negociação entre a metafísica nômade e a metafísica sedentária, tal como cunhado por Cresswell (2006). Tal tensão metafísica, como defendemos, encontra-se subjacente à estrutura do enredo através de três eixos destacados ao longo deste 


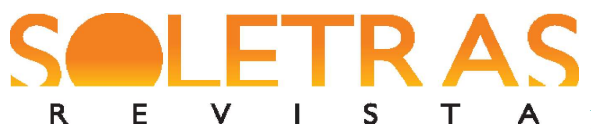

artigo: (i) processos de (re)construção de posições identitárias, (ii) elaboração de um discurso pós-nacional e (iii) a viagem como signo da escrita ficcional, no deslocamento incessante de signos.

Com efeito, prevalece uma tendência a uma perspectiva otimista sobre a experiência de mobilidade, da forma como é imaginada pela autora em Rakushisha, tanto no timbre da dicção - quer sejam dos personagens, quer seja do narrador em terceira pessoa -, quanto nas ações e diálogos evocados pelos personagens protagonistas. Assim, a ficção de Adriana Lisboa, ato contínuo, escapa de um ponto de vista pejorativo, depreciativo a respeito do estatuto da mobilidade, que estaria alinhado, nos termos de Cresswell (2006) à metafísica do sedentarismo; afinal, é o mover-se que permite a Haruki e Celina superarem seus traumas e reconstruírem-se em novas e transitórias posições de sujeito. Para Celina, a deambulação em terra estrangeira é o acicate que a faz apossar-se da pena escritural e enfrentar a zona sombria dos acontecimentos passados envoltos em trauma e luto. Já para Haruki, a ida ao Japão - terra de seu pai- permite ao personagem tornar-se participante cônscio no jogo de suas próprias negociações identitárias, ou, mais precisamente, reconhecer-se na posição simbólica do entrelugar.

Por fim, ressaltamos que há mais camadas do romance a serem averiguadas posteriormente, que não foram foco deste breve artigo que se configura, desse modo, em um percurso inicial de investigação. Em todo caso, é possível afirmar que, aos estudiosos do campo de literatura e mobilidade, Rakushisha apresenta-se como valiosa fonte de pesquisa a respeito das questões imbricadas na relação - antiga, frisa-se - entre literatura e viagem no cenário da produção artística contemporânea.

\section{Referências}

ANDERSON, Benedict. Comunidades imaginadas: reflexões sobre a origem e a difusão do nacionalismo. Tradução de Denise Bottmann. São Paulo: Companhia das Letras, 2008.

ANTELO, Raúl. Mas, onde fica a viagem? Confluenze: rivista di studi ibero americani, Barcelona, Universitá de Bologna, v. 4, n.1, p. 1-14, 2012.

BAKHTIN, Mikhail. Estética da criação verbal. São Paulo: Martins Fontes, 2011. 


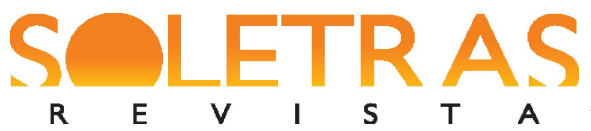

N. 38 - 2019.2 - CLÁUDIO ROBERTO VIEIRA BRAGA BRUNO CARDOSO

BAUMAN, Zygmunt. Modernidade líquida. São Paulo: Jorge Zahar Editor, 2001.

BHABHA, Homi K. O local da cultura. Tradução de Myriam Ávilla et al. Belo Horizonte: Ed UFMG, 2005.

BRAGA, Cláudio R. V.; GONÇALVES, Gláucia R. Diáspora, espaço e literatura: alguns caminhos teóricos. Trama, Marechal Cândido Rondon - Paraná, Unioeste, v. 10, n. 19, abril de 2014.

CARDOSO, Sérgio. O olhar viajante (do etnólogo). In: NOVAES, Adauto (Org.). O olhar. São Paulo: Cia. das Letras, 1988.

CRESSWELL, Tim. On the move: mobility in the modern Western world. New York: Routledge, 2006.

CURY, Maria Zilda Ferreira. Cartografias literárias: Tsubame, de Aki Shimazaki, e Rakushisha, de Adriana Lisboa. Revista Interfaces: Brasil-Canadá, Pelotas - Rio Grande do Sul, UFPEL, v.12, n. 1, p.17-34, abril de 2012.

CURY, Maria Zilda. Memórias da imigração. In: SELIGMANN-SILVA, Márcio (Org.). Palavra e imagem: memória e escritura. Chapecó: Argos, 2006.

GENETTE, Gérard. Discurso da narrativa. 3. ed. Lisboa: Vega, 1995.

GEORGE, Rosemary M. Home-Countries: Narratives across Disciplines. In: . The

Politics of Home. Berkeley: California University Press, 1999.

GERUS-TARNAWECKY, Iraida. Literary Onomastics. Names: a Journal of Onomastics, Londres,n.16: 4, p. 312-324, 1968.

GILROY, Paul. O Atlântico negro: modernidade e dupla consciência. Tradução de Cid Knipel Moreira. Rio de Janeiro: Editora 34, 2001.

HALL, Stuart. A identidade cultural na pós-modernidade. Tradução de Tomaz Tadeu da Silva e Guacira Lopes Louro. Rio de Janeiro: DP\&A, 1999.

LISBOA, Adriana. Rakushisha. Rio de Janeiro: Objetiva, 2014.

.Bondelê \#34: Resenha de Pequena música, mais entrevista com a autora. Entrevista concedida ao Canal Bondelê, 8 jun. 2018. vídeo $(27$ min. $)$. Disponível em: $<$ http://www.youtube.com/watch?v=fBfPtRaGZPM>. Acesso em: 12 mai. 2019.

LOUVEL, Liliane. A descrição pictural: por uma poética do iconotexto. In: ARBEX, Márcia (Org.). Poéticas do visivel: ensaios sobre a escrita e a imagem. Belo Horizonte: UFMG, 2006.

MACHADO, Ana Maria. Recado do nome: leitura de Guimarães Rosa à luz do nome de seus personagens. Rio de Janeiro: Companhia das Letras, 2013. 


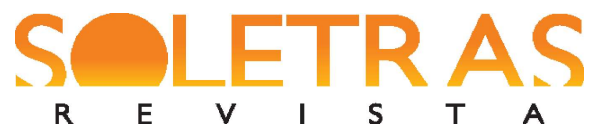

N. 38 - 2019.2 - CLÁUDIO ROBERTO VIEIRA BRAGA BRUNO CARDOSO

PIRES, Maria Isabel Edom. Em viagem: sobre outras paisagens e movimentos no romance brasileiro contemporâneo. Estudos de literatura brasileira contemporânea. Brasília, Distrito Federal, UNB, n. 44, p. 389-403, jul. /dez. 2014.

QUEIROZ, Maria José de. Os males da ausência, ou a literatura do exílio. Rio de Janeiro: Topbooks, 1998.

SAID, Edward. Reflexões sobre o exílio e outros ensaios. Tradução de Pedro Maia Soares. São Paulo: Companhia das Letras, 2003.

THOREAU, Henry David. Caminhando. Tradução de Roberto Muggiati. Rio de Janeiro: José Olympio, 2006. 122 p. (Coleção Sabor Literário)

THOMPSON, Carl. Revealing the Self. In: Travel Writing. New York: Routledge. 2011.

TONUS, José Leonardo. Espaços na e da clandestinidade. In: DALCASTAGNÈ, Regina (Org.). Espaços possíveis na literatura brasileira contemporânea. Porto Alegre: Zulk Editora, 2015 .

URRY, John. The Mobilities Paradigm. In: Mobilities. Cambridge, UK: Polity, 2011.

\title{
Imaginary of mobility in Rakushisha, by Adriana Lisboa: between flow and fixity
}

\begin{abstract}
The article aims to analyze the novel Rakushisha, by Brazilian writer Adriana Lisboa, published in 2007. The analytical framework focuses on actions and images of mobility present in the work, in such a way that the path of investigation shows evidence of how actions and images of mobility are often filled with profound existential meaning, culminating with their protagonist characters in situations of inner discovery or "epiphanic insights about the self", as Thompson (2011) puts it. Based on Carl Thompson (2011) himself, and also on Maria Zilda Ferreira Cury (2012) and Tim Cresswell (2006), the article highlights how the discursive construction of an imaginary of mobility takes place in Rakushisha through a negotiation between metaphysical instances of flow and fixity. This negotiation reveals itself in the protagonists' unstable identities, in the construction of a post national discourse that goes beyond essentialism and national stereotypes and, at last, in the reflections on the very act of writing, built in the metaphor of travel, in the ceaseless movement of signs.
\end{abstract}

Keywords: Mobility vs. Sedentarism. Walking and Gazing. Nation and Identity. Literature as Travel.

Recebido em: 17 de junho de 2019.

Aceito em: 07 de julho de 2019. 